\title{
ANALISIS DE JURISPRUDENCIA DE LA CORTE SUPREMA EN 2001: DERECHO COMERCIAL
}

\author{
Carmen Sfeir Jacir
}

INTRODUCCION; A. Prescripción de la acción cambiaria en pagaré con cláusula de aceleración; B. Acciones cambiarias y acciones extracambiarias; C. Calificación de hecho esencial y deber de informar; $D$. Normas aplicables a la prescripción de la acción para cobrar el pago del porte en el contrato de transporte aéreo; E. Declaración de quiebra por no pago de obligaciones que constan en cheques llamados "en garantía".

\section{INTRODUCCION}

Me ha correspondido comentar cinco fallos dictados por la excelentísima Corte Suprema de Justicia durante el año 2001 relativos a materias propias del Derecho Comercial. Estos cinco fallos dan cuenta de los siguientes problemas: a) Acciones Cambiarias y Extra cambiarias y su prescripción; b) Cheques llamados "en garantía” y; c) La calificación de "hecho esencial" y la obligación de informar acerca de tales hechos, establecida la Ley de Mercado de Valores y la Ley sobre Sociedades Anónimas. Este último tema tiene especial relevancia en estos tiempos, en que la transparencia y la oportunidad de la información en los mercados de capitales, ha cobrado particular dimensión con los escándalos financieros de empresas como Enron, Worldcom y Adelphia, entre otras. La información en materia de valores resulta fundamental, particularmente en nuestro mundo globalizado, a fin de que los inversionistas efectúen sus decisiones basándose en la datos fidedignos a fin de impedir que se asuman riesgos distintos de aquellos que son propios de las transacciones de valores.

\section{A. Prescripción de la acción cambiaria en pagaré con cláusula de aceleración}

En Banco de Chile contra Norberto Weitzmann Jaraj y otro, ${ }^{1}$ la Corte Suprema, a propósito del conocimiento de un recurso de casación en el fondo, debió resolver nuevamente un asunto que no llega a ser pacífico en la jurisprudencia, no obstante numerosos fallos en el mismo sentido. Se trata de la aplicación, a la acción de cobro del pagaré, de la regla de prescripción del artículo 98 de la Ley 18.092, sobre Letra de Cambio y Pagaré y de la época desde la que se cuenta dicho plazo.

En el presente caso, don Norberto Weitzmann Jaraj suscribió un pagaré por U.F. 320,54 , con 36 vencimientos mensuales y sucesivos, debiendo efectuar el primer pago el 5 de agosto de 1994. Para garantizar esta obligación, la empresa Forestal y Transportes Trilaleo Limitada se constituyó en avalista y codeudora solidaria.

\footnotetext{
* Lic. Cs. Jcas. y Socs. (U. Ch.), LL.M. (Duke). Profesora asistente, Facultad de Derecho, Universidad de Chile. ${ }^{1}$ Rol N²492-9911 de Abril de 2001.
} 
El deudor principal sólo pagó algunas cuotas y luego ingresó a la cartera impaga del Banco, el 5 de diciembre de 1995, adeudando a esa fecha U.F. 192,82, más los intereses pactados. En virtud de una cláusula de aceleración facultativa pactada en el pagaré, el Banco de Chile demandó ejecutivamente, con fecha 19 de marzo de 1996, al suscriptor del pagaré y a su avalista, por el total adeudado de U.F. 192,82, más el interés pactado desde la fecha de la mora y hasta la del pago efectivo.

El ejecutado se notificó de la demanda con fecha 14 de enero de 1998, oponiendo en el mismo acto la excepción de prescripción de la acción intentada. Fundó su excepción en la circunstancia que había transcurrido más de un año desde que el ejecutante presentó la demanda, momento en que se hizo efectivo el crédito y se puso en vigencia la cláusula de aceleración y la fecha en que el ejecutado se notificó de la demanda, el 14 de enero de 1998.

La primera de las cuestiones debatidas en este proceso es la regla de prescripción a aplicar a la acción de cobro emanada del pagaré. Al oponer su excepción de prescripción el ejecutado señala que al pagaré le es aplicable lo dispuesto en el artículo 98 de la Ley 18.092, que dispone: "El plazo de prescripción de las acciones cambiarias del portador contra los obligados al pago es de un año, contado desde el día del vencimiento del documento." Lo anterior, por aplicación de lo dispuesto en el artículo 107 de la misma ley, que hace aplicables al pagaré, en lo que no sean contrarias a su naturaleza, las disposiciones relativas a la letra de cambio, dentro de las cuales se encuentra la regla de prescripción de la acción cambiaria, recién enunciada.

Por su parte, el ejecutante refuta esta afirmación señalando que la regla aplicable al caso, en lo que a la prescripción respecta, es la del artículo 822 del Código de Comercio, que establece un plazo de cuatro años para la prescripción de las acciones, contado desde el vencimiento del crédito.

Agrega el ejecutante, en su escrito de apelación, que la regla de prescripción del Código de Comercio recién referida, le es aplicable al documento cuyo cobro ejecutivo pretende, por cuanto se trata de un documento con vencimientos sucesivos y no con un solo vencimiento. Explica que el artículo 48 de la Ley 18.092 en su inciso final señala que "No vale como letra de cambio la girada a otros vencimientos o a vencimientos sucesivos". Lo anterior indicaría que la regla de prescripción del artículo 98 de la ley señalada, solo se aplicaría a títulos de crédito que tengan un único vencimiento y no a aquellos, como el pagaré con vencimientos sucesivos, como el del caso sub lite, pues ello sería contrario a la naturaleza misma de la letra de cambio (artículo 107 de la Ley 18.092).

$\mathrm{Al}$ respecto, el fallo en comento rechaza la tesis del ejecutante por cuanto la regla del artículo 107 es clara en extender la aplicación de las normas de la letra de cambio al pagaré en todo aquello que no contravenga su naturaleza.

En efecto, se señala que los vencimientos sucesivos del pagaré están en íntima y directa relación con la época del pago. El pagaré fragmentado en cuotas o mensualidades es simplemente una deuda a plazo y la época del pago es una mención no esencial del pagaré. Esencial, indica el fallo, significa de la naturaleza de las cosas. En conclusión, la época del pago (y cómo ésta se divide) no es de la naturaleza del pagaré y no siendo así, el pagaré con vencimientos sucesivos no contraviene la naturaleza de la letra de cambio, lo que hace del todo aplicable la norma sobre prescripción del artículo 98 de la Ley 18.092. 
La segunda cuestión en análisis, una vez establecida la regla de prescripción a aplicar a la acción de cobro del pagaré, es el plazo a partir del cual comienza a correr la prescripción establecida en el artículo 98, tantas veces citado.

El ejecutante sostiene que, para el caso de aplicarse la regla de prescripción de la acción cambiaria, el plazo, en el caso del pagaré con vencimientos sucesivos, debe contarse a partir de la última cuota pactada y en subsidio, desde la notificación de la demanda ejecutiva.

La Corte, en este punto, resolvió nuevamente a favor del ejecutado, en cuanto sostuvo que habiéndose pactado una cláusula de aceleración facultativa y habiendo el Banco presentado la demanda ejecutiva, en la que manifestó claramente su intención de cobrar el monto total del saldo insoluto de la deuda, es decir de hacer efectiva y vigente la cláusula de aceleración, el plazo debe contarse desde ese preciso momento. Agrega que la notificación es necesaria para la formación de la relación procesal, pero no lo es para el ejercicio del derecho que da la cláusula de aceleración.

En efecto, se distinguen dos situaciones en relación con el plazo para contar la prescripción de la acción de cobro emanada del pagaré: la primera y regla general, es que el plazo de prescripción se cuenta desde la fecha de vencimiento de la última cuota. En este caso, la Corte estimó que no hay tantas obligaciones como cuotas, sino varios pagos estipulados aunque la obligación sigue siendo una sola y la fecha de vencimiento del documento corresponde, en general, al vencimiento de la última cuota de pago en que fue dividida la obligación. ${ }^{2}$

Sin embargo, cuando se pacta una cláusula de aceleración o estipulación de caducidad del plazo, de acuerdo al artículo 105 de la Ley 18.092, y el portador del pagaré hace efectiva dicha cláusula por el total del saldo insoluto por la interposición de una demanda ejecutiva, hace vencer el plazo del pagaré desde ese momento, en el cual evidencia su intención de ejercer los derechos que le otorga la cláusula de aceleración.

\footnotetext{
2 En lo relativo a la fecha a partir de la cual debe contarse el plazo de prescripción del artículo 98 de la ley 18.092, en el caso del pagaré con vencimientos sucesivos, la doctrina ha considerado las siguientes alternativas: a) Como cada cuota tiene vencimiento separado, el plazo de prescripción se cuenta independientemente. Esto es, la acción para el cobro de cada cuota prescribe independientemente, empezándose a contar su plazo desde el vencimiento de la cuota.

b) Como el plazo de prescripción se empieza a contar desde el vencimiento del documento, por disponerlo así el artículo 98 y el documento vence con la última cuota, es desde esa fecha que debe empezar a correr el referido plazo.

La jurisprudencia se ha inclinado mayoritariamente por la segunda de las alternativas ...La cláusula de aceleración o exigibilidad anticipada no altera dicha situación por cuanto tal cláusula opera en beneficio exclusivo del acreedor quien no está obligado a demandar necesariamente al vencimiento de cada una de las cuotas insolutas.

No obstante lo expuesto, también se ha fallado que procede acoger la excepción de prescripción opuesta por el ejecutado si consta que, a la fecha en que se demandó ejecutivamente a las personas obligadas al pago del pagaré, había transcurrido en exceso el plazo de un año contado desde la fecha en que el ejecutante hizo vencer el documento, haciendo uso de la cláusula de aceleración estipulado en el mismo, considerándose así este documento vencido para todos los efectos legales.

Ubilla Grandi, Luis Eugenio, Teoría General de la Letra de Cambio y del Pagaré en la Ley 18.092, p. 107s, Santiago: Ed. Jca. de Chile (1990).
} 
Finalmente, cabe destacar que concurrió a este fallo el ministro Sr. Rodríguez, quien estimó que en el título del ejecutante no se estableció una fecha única de vencimiento, sino tantas como las correspondientes a las cuotas mensuales y sucesivas de pago. Si bien el acreedor quedó facultado para cobrar el monto total insoluto en caso de incumplimiento de alguna de las obligaciones del deudor, no es menos cierto que una vez ejercido este derecho mediante la presentación de la demanda, es menester que el deudor tome conocimiento de ello. Lo anterior sólo se logra mediante la notificación de la demanda. ${ }^{3}$ En estas circunstancias, en el caso de autos correspondía declarar la prescripción extintiva de la acción ejecutiva sólo respecto de aquellas cuotas pendientes de pago antes de la notificación de la demanda, el 14 de enero de 1997, pero no respecto de las cuotas que vencían con posterioridad a esa fecha ya que el plazo de prescripción de un año no se había cumplido respecto de ellas. Concluye notando que lo expuesto no fue señalado por el recurrente como error de la sentencia, por lo que no cabe anularla ni reemplazarla en tal sentido.

\section{B. Acciones cambiarias y acciones extracambiarias}

La Sociedad Callegari e Hijos Ltda. vendió un automóvil al demandado. El precio fue pagado con un crédito que el comprador obtuvo del Banco de Crédito e Inversiones, con el aval solidario de la sociedad demandante, lo que consta en un pagaré, con vencimientos sucesivos, suscrito el 31 de diciembre de 1992. Habiendo el suscriptor del pagaré cesado en el pago de la mayor parte de las 24 cuotas en que estaba dividida la obligación, el demandante se vio obligado a responder del pago de las sumas adeudadas al Banco. En virtud del pago efectuado por el demandante, en su calidad de avalista y codeudor solidario del suscriptor del pagaré, éste interpuso demanda en juicio ordinario a fin de que el demandado le reembolsara las sumas pagadas por él.

La Sociedad Callegari e Hijos Ltda. dedujo demanda ordinaria de cobro de pesos solicitando se declarase la obligación del suscriptor del pagaré de pagarle la cantidad que ella, en su calidad de avalista y codeudora solidaria del demandado, pagó al tenedor de dicho título de crédito. Para fundamentar su demanda citó los artículos 46, 47 inciso $2^{\circ}, 82$ y 85 y siguientes de la Ley 18.092, y los artículos 253 y siguientes del C.P.C. La parte demandada señaló en su escrito de contestación que la acción que la demandante ejercía era la cambiaria de reembolso, regulada por el artículo 82, inciso $3^{\circ}$ de la Ley 18.092, que tiene un plazo de prescripción de seis meses, según el artículo 99 de la misma ley. Este plazo habría transcurrido con creces al momento de la notificación de la demanda. Así, la controversia no se encuentra en la existencia del pago efectuado por el demandante, ni en la existencia de la deuda correspondiente, sino en el procedimiento para su cobro y las reglas de prescripción que le son aplicables.

En primera instancia, el tribunal resolvió, sin mayor fundamento legal, que pretendiendo la demandante que se le reembolse, entendiendo esta palabra en su sentido

\footnotetext{
${ }^{3}$ La razón que se da para entender que el plazo se cuenta desde la notificación de la demanda y no desde la fecha de presentación de la misma, es que esta última fecha no es un término cierto, ya que existen distintas fechas a considerar como la de ingreso a distribución de la corte, la de ingreso al tribunal competente, la de notificación por el estado diario de la resolución que provee la demanda. Sin perjuicio de lo anterior, la demanda puede ser retirada antes de ser proveía y aún antes de ser notificada. Vid. Pumpin Valck, Gabriel, "La Letra de Cambio y el Pagaré: El Factor Tiempo y Tributario en el Ejercicio de las Acciones Cambiarias," p. 21s, memoria de prueba, Universidad Católica de Chile (1988).
} 
natural y obvio, esta acción de reembolso debe impetrarse dentro de los plazos de prescripción a que se encuentre sometida y reglada la obligación cuya repetición se desea. De manera que si la acción proviene de un contrato civil, deberán aplicarse a ella las reglas de prescripción del Código Civil, establecidas en los artículos 2492, 2514 y 2515 del mismo. En tal caso, la acción prescribiría en el plazo de cinco años, por tratarse de una acción ordinaria. Por el contrario, tratándose de una acción mercantil, la prescripción que correspondería aplicar sería la de la acción cambiaria de reembolso establecida en el artículo 82 de la Ley 18.092, que por aplicación del artículo 99 del mismo cuerpo legal, prescribe en el plazo de seis meses.

En atención a lo anterior, y para efectos de determinar la naturaleza de la acción, correspondía, en opinión del tribunal, dilucidar la naturaleza de la obligación cuyo reembolso se intentaba (civil o mercantil). El tribunal determinó que se trataba de una obligación mercantil, toda vez que ella emana del pagaré, título de crédito que es eminentemente mercantil y que la acción derivada de tal obligación es justamente la acción cambiaria de reembolso que emana de la letra de cambio y del pagaré. Por estas razones, el tribunal de primera instancia acogió la prescripción alegada por la parte demandada. La Corte de Apelaciones de La Serena confirmó el fallo sin modificaciones substanciales.

La Corte Suprema, conociendo del recurso de casación en el fondo y haciendo uso de su facultad de casar de oficio, anuló la sentencia referida precedentemente por el vicio de casación de forma contemplado en el $\mathrm{N}^{\circ} 5^{\circ}$ del artículo 768 del Código de Procedimiento Civil, es decir, por haber sido pronunciada con omisión de cualquiera de los requisitos enunciados en el artículo 170 del mismo Código, en relación con el $\mathrm{N}^{\circ} 4^{\circ}$ del artículo 170 citado, que dispone como mención de todo fallo 'las consideraciones de hecho y de derecho que sirven de fundamento a la sentencia.' ${ }^{4}$

El fallo de casación de la Corte Suprema se funda en que la sentencia recurrida, no contiene los fundamentos necesarios para concluir que en autos se ejercitó la acción cambiaria de reembolso. Tiene presente que la sociedad demandante ejerció una acción ordinaria en contra del demandado, para obtener la devolución de una suma de dinero que pagó por él en virtud de la obligación contraída con el Banco de Crédito e Inversiones y que en la réplica, el demandante no dejó lugar a dudas en cuanto a la naturaleza ordinaria de la acción que ejerció.

Las acciones cambiarias, sostiene el máximo tribunal, son aquellas que emanan de la letra de cambio y del pagaré y que son distintas e independientes de las acciones extracambiarias o derivadas del negocio causal. Este criterio resulta del todo concordante con la jurisprudencia anterior del máximo tribunal, en que sostiene que:

La norma contenida en el artículo 2515 del Código Civil, que dispone que las acciones ejecutivas que hayan prescrito como tales, subsisten como ordinarias por el plazo de tres años, es un precepto de aplicación general y por ende rige respecto de los pagarés y las letras de cambio.

Las circunstancia que los títulos de crédito tengan el carácter de autónomos o independientes de la relación jurídica a que obedecen y abstractos, por carecer de causa, refuerzan la conclusión precedente. ${ }^{5}$

\footnotetext{
${ }^{4}$ Rol N²802-2000, de 7 deMayo de 2001.

${ }^{5}$ Rdj t 97 p. II- 8.
} 
Sfeir - Jurisprudencia Corte Suprema 2001: Derecho Comercial

El fundamento utilizado por los jueces del fondo, en el sentido de estimar que el actor ha ejercido la acción de reembolso, por el solo hecho de sostener que el demandado debe reembolsar las sumas de dinero que pagó por él, resulta insuficiente como fundamento para estimar que se trata de una acción cambiaria de reembolso. Existen disposiciones legales que utilizan el término reembolsar sin referirse a las acciones que emanan de la letra de cambio o del pagaré, como es el caso del artículo 2370 del Código Civil.

Por tales razones y actuando de oficio, la Corte invalidó el fallo por el vicio de casación en la forma precedentemente enunciado y dictó sentencia de reemplazo, rechazando la excepción de prescripción opuesta por el demandado y acogiendo la demanda de autos. Para hacer esto, estimó que lo que se produjo en la especie, aunque el demandante omitiese expresarlo, fue un pago con subrogación en los términos del artículo 1612 del Código Civil, es decir, la ficción jurídica en virtud de la cual un crédito que ha sido pagado con el dinero suministrado por un tercero, y que queda por tanto extinguido respecto del acreedor, se reputa subsistir íntegramente con todos sus accesorios, en manos de ese tercero para asegurarle el reembolso de lo que pagó.

El buen criterio de la Corte resulta evidente en este caso, toda vez que la doctrina unánimemente ha señalado que las obligaciones cambiarias tienen un carácter abstracto, lo que significa que teniendo estas obligaciones causa, al igual que deben tenerla todas las obligaciones, ésta es independiente, respecto del portador de una letra de cambio o de un pagaré, de la existencia y validez de la relación subyacente, la que constituye la causa de la suscripción de dicho documento. La expresión causa en este caso, se utiliza más bien como la razón por la cual una persona contrajo una obligación cambiaria.

De esta afirmación se desprende forzosamente que si la causa por la cual se suscribió el título de crédito es independiente del mismo, además de las acciones cambiarias que derivan de dicho documento, es posible al titular ejercer las acciones ordinarias que emanan de la obligación subyacente y que tienen plazos de prescripción más extensos que los de las acciones cambiarias.

En el caso en análisis, existían dos obligaciones: la de reembolso emanada de la letra de cambio o pagaré, cuyo cumplimiento debe reclamarse a través de la acción cambiaria; y la obligación que emana del hecho de haber pagado el avalista al acreedor, por lo cual aquel tiene acción ordinaria contra el deudor principal para recuperar lo pagado. Ambas acciones son independientes entre sí y la prescripción de una de ellas no afecta el ejercicio de la otra.

Confirma esta posición el $\mathrm{N}^{\mathrm{o}} 17^{\circ}$ del artículo 464 del Código de Procedimiento Civil, que establece como una de las excepciones que puede oponer el ejecutado, "la prescripción de la deuda o solo de la acción ejecutiva." Esta norma distingue claramente que existirán casos en que si bien la acción ejecutiva, como es la acción cambiaria de reembolso, se encuentra prescrita, la deuda, es decir la obligación subyacente por la cual se suscribió el pagaré, puede encontrarse perfectamente vigente, tal como en la situación que tocó fallar en este caso.

\section{Calificación de hecho esencial y deber de informar}


En la presente causa, la Corte Suprema rechaza dos recursos de casación en el fondo presentados por la Superintendencia de Valores y Seguros y por el representante de los directores de Enersis S.A., respectivamente. ${ }^{6}$

El caso se originó por reclamo judicial interpuesto por los miembros del directorio de Enersis S.A. ${ }^{7}$ en contra de la Resolución 331 de la Superintendencia de Valores y Seguros, de 23 de octubre de 1997, mediante la cual se aplica a los directores de la empresa referida una multa de U.F. 1.000, de la que debían responder personal y solidariamente.

El motivo de la sanción impuesta por la autoridad, fue el incumplimiento, por parte del directorio de Enersis S.A. del requerimiento que dicha Superintendencia le formuló, mediante la Resolución 305, de 6 de octubre de 1997:

para que [sesionara] en el más breve plazo que le [permitiera] el artículo 40 del Reglamento de Sociedades Anónimas, a fin de que se [pronunciara] sobre el acuerdo de alianza estratégica con Endesa España celebrado por el gerente general y [determinara] la esencialidad o no de sus disposiciones, debiendo adoptar los acuerdos de informar al público en general sobre las materias que tengan dicho carácter.

La resolución sancionatoria expresa que el directorio no se pronunció sobre la esencialidad de la alianza estratégica y no comunicó el eventual hecho esencial.

El reclamo deducido por el directorio de Enersis S.A. se funda en que, en opinión de los directores reclamantes, no se precisa cuál es la conducta sancionada, ya que en la resolución reclamada se señala que el directorio no se pronunció sobre la esencialidad de la alianza estratégica y no se había comunicado ese hecho esencial, en circunstancias que existía un expreso pronunciamiento acerca de la esencialidad de la alianza estratégica, como también comunicación del hecho esencial a la autoridad. Señalan que respecto del 'texto de la alianza' suscrito por el gerente general de Enersis S.A., José Yuraszeck, el directorio lo estimó inoponible, por cuanto el Gerente se habría excedido en sus facultades al suscribirlo, además de adolecer dicho acuerdo de 'otros defectos' legales que podrían restarle valor. Por esta razón habría sido improcedente y contradictorio publicar dicho texto como acto de Enersis S.A., ya que sería reconocerle valor a dicho acuerdo, y que dicha opinión había sido comunicada a la Superintendencia de Valores y Seguros en su oportunidad.

Los reclamantes estiman que el motivo de la sanción es precisamente no haberse pronunciado sobre la esencialidad del texto de la alianza estratégica y no haber comunicado este hecho a la Superintendencia, de acuerdo con los artículos 9 y 10 de la Ley sobre Mercado de Valores, en circunstancias que consideran improcedente e inconveniente esta conducta, toda vez que estimaron inoponible el referido texto.

Es así que los miembros del directorio de Enersis S.A., estiman infringidos los artículos 10 letra f), 27 del D.L. 3.538 y 58 de la Ley 18.045, que se refieren a la atribución de la Superintendencia de aplicar sanciones a las infracciones a esa ley, sus normas complementarias, estatutos y reglamentos internos y resoluciones que dicte dicha

\footnotetext{
${ }^{6}$ Rol N¹422-2000, 12 de Julio de 2001.

7 A excepción del presidente del directorio de Enersis S.A., quien interpuso reclamo separado.
} 
autoridad; y artículo 133 de la Ley 18.046, que establece la responsabilidad por infracciones a dicha ley, su reglamento o, en su caso, los estatutos sociales o las normas que imparta la Superintendencia.

Todos estos errores constituirían una infracción a la igual protección que la ley debe dar a las personas en el ejercicio de sus derechos, garantizado en el $\mathrm{N}^{\circ} 3^{\circ}$ del artículo 19 de la Constitución Política del Estado, y a los artículos $6^{\circ}$ y $7^{\circ}$ de la misma carta fundamental, por cuanto la autoridad sancionadora sólo puede actuar dentro del marco de las atribuciones que le señala la ley.

Además, se acumula a esta causa la demanda en juicio sumario, interpuesta por don Luis Fernando Mackenna Echaurren en contra de la Superintendencia de Valores y Seguros, en carácter de reclamación que le da derecho el artículo 30 del D.L. 3.538, contra la Resolución 331, ya referida, mediante la cual la Superintendencia le impuso una multa, junto con los demás directores de Enersis S.A., con quienes debe responder solidariamente, de U.F. 1.000. Fundamenta su demanda en el hecho que, como presidente del directorio de Enersis S.A., tan pronto como recibió la Resolución 305 de la Superintendencia de Valores y Seguros, citó al directorio para que se pronunciara sobre la esencialidad del acuerdo de alianza estratégica. En la sesión de directorio que se celebró al efecto instó repetidamente al órgano de administración de la empresa a dar cumplimiento a esta exigencia. No obstante haber desplegado todas estas conductas, no pudo por sí solo alterar el curso de las deliberaciones y estima que por ello no le asiste responsabilidad alguna en la omisión que motiva la sanción administrativa.

El tribunal de primera instancia falló rechazando la demanda presentada por los directores de Enersis S.A. Acogió sin embargo la demanda deducida por don Luis Fernando Mackenna Echaurren. El fallo se fundó en que de acuerdo con los artículos 9 y 10 de la Ley de Mercado de Valores, los directores de una sociedad anónima están sujetos a la obligación de informar, que consiste en "divulgar en forma veraz, suficiente y oportuna toda información esencial respecto de sí mismo, de los valores ofrecidos y de la oferta." Es por ello que la autoridad tiene la facultad de instar a los demandantes a adoptar un pronunciamiento sobre la esencialidad de la alianza estratégica con Endesa España, ya que ello es una medida que beneficia al mercado, a fin de que sus agentes puedan adoptar sus decisiones contando con la información adecuada y necesaria al efecto. Esta obligación consta también en el artículo 46 de la Ley 18.046, que señala que el directorio de una sociedad anónima "deberá proporcionar a los accionistas y al público, las informaciones suficientes, fidedignas y oportunas que la ley $y$, en su caso, la Superintendencia determinen respecto de la situación legal, económica y financiera de la sociedad."

Si los directores demandantes estimaban que el requerimiento de la Superintendencia era improcedente, contaban con un procedimiento legal para impugnarla. Se trata de la reclamación consagrada en el artículo 46 del D.L. 3.538, que permite a los afectados, dentro del plazo que ella establece, impugnar, mediante un procedimiento especial, toda norma general, instrucción, comunicación resolución u omisión de la Superintendencia, cuando ella sea ilegal o cause un perjuicio al destinatario.

El tribunal de primera instancia estimó que, sin perjuicio de que el directorio de la empresa facultó al gerente general para comunicar a la autoridad la celebración de un contrato de alianza estratégica- lo que efectuó dicho Gerente con fecha $1^{\circ}$ de agosto de 
1997- esta comunicación no garantiza que se haya emitido un pronunciamiento serio por parte del directorio, sobre un contrato de alianza estratégica, antes de su celebración y conocimiento por quienes deben adoptar el pronunciamiento acerca de la esencialidad de dicho acuerdo. Por ello, la Superintendencia estaba facultada para requerir del directorio un pronunciamiento concreto, formal y especifico acerca de la esencialidad de la alianza estratégica.

En cuanto a la alegación de inoponibilidad de la alianza estratégica suscrita por el gerente general, en razón de haber supuestamente excedido sus facultades, el tribunal resolvió que la inoponibilidad es una sanción civil relativa a los efectos de un acto o contrato respecto de terceros. Pero dicha sanción no ataca el valor del acto en sí mismo, sino más bien, la extensión de sus efectos. La alianza estratégica fue suscrita por el gerente general, quien fue debida y ampliamente facultado para ello, razón por la que el tribunal no divisa una extralimitación de facultades por parte de dicho gerente general.

Adicionalmente, nada obstaba para que el directorio de la empresa acordara hacer expresa reserva de los derechos de la misma para alegar la inoponibilidad del acuerdo, cuya existencia no pudo ser ignorada por el órgano de administración, en especial si se considera la profusa difusión que el acuerdo tuvo en los medios de comunicación, lo que tuvo connotación en el mercado bursátil.

Así las cosas, la negativa del directorio de Enersis S.A. de pronunciarse sobre la esencialidad del texto de la alianza estratégica, de acuerdo al requerimiento formulado por la Superintendencia de Valores y Seguros, mediante la Resolución 305, carece de justificación. Lo anterior resulta particularmente efectivo, tomando en cuenta que dicho directorio fue convocado especialmente a sesionar a fin de pronunciarse sobre esta materia, para lo cual fue reiteradamente instado por el presidente del mismo durante dicha sesión.

Contrario a lo señalado por los demandantes, la Superintendencia no ha excedido sus facultades, ni se ha inmiscuido en la administración de la empresa o propuesto al directorio una decisión determinada respecto de la alianza estratégica, sino que le ha solicitado un pronunciamiento acerca de la esencialidad de dicho acuerdo a objeto de que el mercado y sus agentes cuenten con la oportuna y correcta información que le permita tomar sus decisiones bursátiles. De haber estimado el directorio que la Resolución de la autoridad no se ajustaba a derecho, debió reclamar de ella, ejerciendo oportunamente la acción correspondiente.

Finalmente el tribunal de primera instancia rechazó la acción subsidiaria entablada por los directores de Enersis S.A., en cuanto solicitaron la rebaja de la multa impuesta por la autoridad, por estimar dicha solicitud carente de fundamento.

La Corte de Apelaciones de Santiago confirmó este fallo y agregó como fundamento de la resolución confirmada, que el directorio de Enersis S.A., en lugar de dar cumplimiento a la Resolución 305 de la Superintendencia, en la sesión de directorio citada al efecto por su presidente, esto es, pronunciarse sobre la esencialidad de la alianza estratégica con Endesa España, entró a calificar los efectos legales de orden civil que revestiría dicho acuerdo suscrito por el gerente general, estimando que dicha alianza le era inoponible. En consecuencia, sin fundamento alguno, el directorio consideró legítimo omitir el pronunciamiento requerido por la autoridad sobre la esencialidad del acuerdo. 
La Corte Suprema se pronunció sobre el recurso de casación interpuesto por los directores de Enersis S.A. rechazando todos los capítulos de dicho recurso por los fundamentos que se expone a continuación.

1. Infracción a los artículos 1702 y 1704 del Código Civil, en relación con los artículos $9^{\circ}$ y 10 de la Ley 18.045, por cuanto los recurrentes estiman que el directorio cumplió con su obligación de informar cuando comunicó mediante carta acompañada en autos a la Superintendencia la calificación de hecho esencial de la suscripción de una alianza estratégica con Endesa España y que, en razón de que dicha carta -instrumento privado presentado en juicio- no ha sido objetada, ha adquirido valor de escritura pública y demuestra que el directorio de Enersis S.A. dio cumplimiento a su obligación de informar el hecho esencial en cuestión, circunstancia que el fallo recurrido no habría considerado al resolver.

A este respecto la Corte concuerda con lo resuelto por los jueces del fondo:

No resulta aceptable que haya habido un pronunciamiento serio sobre la esencialidad de las cláusulas de un contrato, antes de que éste haya sido celebrado y conocido por quienes están llamados a adoptar dicho pronunciamiento. Como parece evidente, una cosa es la esencialidad de un contrato que se proyecta suscribir - cosa que hizo el directorio de Enersis S.A. al autorizar a su Gerente General para suscribirlo- y otra muy diferente la de pronunciarse sobre la esencialidad una vez suscrito, cual era el requerimiento de la autoridad a los reclamantes.

En este punto es necesario tener presente que, mediante fallo pronunciado con ocasión de la interposición de un recurso de casación en el fondo en la causa Yuraszecck Troncoso, José Roberto con Superintendencia de Valores y Seguros, la Corte Suprema consideró oportuna la comunicación de hecho esencial de la futura suscripción del contrato de alianza estratégica, efectuada por el gerente general de Enersis S.A., y señaló que

La finalidad de la normas que el recurrente (la Superintendencia) dice haberse violado por los sentenciadores (artículos $9^{\circ}$ inc. $1^{\circ}$ y 10 , inc. $2^{\circ}$, de la Ley 18.045) no es sino que la autoridad, el mercado y los inversionistas tengan conocimiento de la información calificada de esencial al momento de realizar sus operaciones comerciales, lo que en la especie ha ocurrido en forma oportuna, debiendo ser desechada la alegación referida. ${ }^{8}$

La Corte indica que los documentos en cuestión han sido agregados en autos y se les ha dado el mérito probatorio que corresponde, sin que de éste se pueda desprender de manera alguna que los demandantes dieron cumplimiento a la resolución que motivó la multa impugnada.

2. Infracción a los artículos $9^{\circ}$ y 10 de la Ley 18.045 , en relación al artículo 46 de la Ley 18.046; 10, letra f), $27 \mathrm{~N}^{\circ} 2^{\circ}, 28 \mathrm{~N}^{\circ} 2^{\circ}$ y 30 inciso $1^{\circ}$ del D.L. 3.538, por estimar los recurrentes contradictorio el requerimiento efectuado por la autoridad en cuanto a pronunciarse sobre la esencialidad de un acuerdo que el órgano de administración de la empresa consideró inoponible. De acuerdo con los recurrentes, lo que debe declararse como esencial o no, son los hechos propios de Enersis S.A. que la vinculen u obliguen.

8 Rdjt 97 p. V-109. 
En este aspecto la Corte estima correcto el criterio sostenido por la sentencia de primera instancia, confirmada por el fallo recurrido, en el sentido que si el gerente general excedió o no sus atribuciones, no es ésta una materia atingente a la discusión de autos y que las normas infringidas, así como el requerimiento de la autoridad, obligaban al directorio a emitir un pronunciamiento que se omitió deliberadamente.

3. Infracciones a los artículos 2131 y 2160 del Código Civil, en relación con el artículo 2079 del mismo Código y artículos $9^{\circ}$ y 10 de la Ley 18.045, por cuanto la sentencia recurrida señala, erradamente en concepto de los recurrentes, que el directorio carece de la facultad de declarar la inoponibilidad de un acto por sí mismo. Estiman los recurrentes que la inoponibilidad, a diferencia de otras sanciones civiles es una suerte de inexistencia de los efectos de ciertos actos o contratos respecto de terceros que no concurrieron a suscribirlos o celebrarlos y que no requiere de declaración judicial.

La Corte desestimó de inmediato este argumento, por cuanto se fundamentan en un supuesto no demostrado en autos, cual es que el Gerente Sr. Yuraszeck se excedió en su mandato. Y como dicha circunstancia no quedó establecida como efectiva, tampoco pueden los recurrentes continuar sosteniendo que el acuerdo de alianza estratégica les era inoponible y que por ello se excusan de no haber emitido pronunciamiento sobre la esencialidad de ese hecho.

Por otra parte el recurso de casación en el fondo interpuesto por la Superintendencia de Valores y Seguros, también es rechazado por el tribunal supremo. Dicho recurso se fundó en dos grupos de infracciones. En cuanto al primero de ellos, ${ }^{9}$ los recurrentes señalan que la Superintendencia sostuvo que está reconocido en autos el hecho de que el Sr. Mackenna, presidente del directorio, votó favorablemente cuatro de los cinco acuerdos adoptados en la sesión de directorio a que citó para que el directorio se pronunciara sobre el requerimiento de la autoridad, y que solo se abstuvo de votar en uno de ellos. Según la recurrente, si este director pretendía salvar su responsabilidad, debió haber hecho constar su oposición, ya que la simple abstención no puede ser sinónimo de oposición y no es una conducta contemplada en la ley como liberadora de responsabilidad.

Respecto del segundo grupo de errores ${ }^{10}$, la recurrente estima básicamente que se ha liberado al Sr. Mackenna de la multa impuesta al resto de los directores, sin que mediara fundamento legal alguno al respecto.

La Corte resolvió que en la sesión de directorio convocada por su presidente, Sr. Mackenna, para que aquel se pronunciara sobre el requerimiento efectuado por la Superintendencia mediante la Resolución 305, no le cabía a dicho presidente dejar constancia alguna sobre su oposición para salvaguardar su responsabilidad, ya que la constancia a la oposición acerca de un acuerdo del directorio solo le habría sido exigible en el evento que el directorio hubiese hecho el pronunciamiento solicitado, lo que no ocurrió en el caso de autos. Por esta razón no podía el presidente del directorio dejar constancia de su oposición a un pronunciamiento que no fue adoptado.

${ }_{9}^{9}$ En que se alegaron como infringidos los artículos 47 , incisos $1^{\circ}$ y $4^{\circ}, 48$ incisos $1^{\circ}, 3^{\circ}$ y $4^{\circ}$ y 133 incisos $1^{\circ}$ y $3^{\circ}$ de la Ley 18.046; 10, letra f), 27 inciso $1^{\circ}$ y $\mathrm{N}^{\circ} 2^{\circ}$ del inciso $2^{\circ}$ del D.L. 3.538 ; y 19 inciso $1^{\circ}$ y 22 inciso $2^{\circ}$ del Código Civil.

${ }^{10}$ En que se alegaron como infringidos los artículos 133 incisos $1^{\circ}$ y $3^{\circ}$ de la Ley 18.046, 10 letra f), $27 \mathrm{~N}^{\circ} 2^{\circ}$ inciso $2^{\circ}$ del D.L. 3.538; y 19 inciso $1^{\circ}$ del Código Civil. 
Sfeir - Jurisprudencia Corte Suprema 2001: Derecho Comercial

En conclusión, el fallo de la Corte Suprema deja en claro nuevamente el carácter imperativo del deber de información a que están sujetos los administradores de sociedades anónimas, cuando así lo requiere la ley o Superintendencia de Valores y Seguros.

\section{Normas aplicables a la prescripción de la acción para cobrar el pago del porte en el contrato de transporte aéreo}

La discusión en este caso se inicia por demanda de cobro de pesos que constan en facturas, interpuesta por "Pacific Steam Navigation Company", agencia de transportes, en contra de "Greenpeace S.A." Las facturas dan cuenta del valor de varios pasajes emitidos por diversas líneas aéreas, que la demandada compró a través de la demandante y que no pagó, debiendo la actora solucionar dichos valores con fondos propios.

La demandada alega en su defensa la prescripción de la acción para demandar el costo del flete, por aplicación de los artículos 2.522 y 2.013 del Código Civil y artículos 126 y 6 del Código Aeronáutico, que permiten concluir que las acciones de los transportistas y acarreadores prescriben en el plazo de un año, el cual ha transcurrido sobradamente en el caso de autos. En subsidio, solicita se rechace la demanda por cuanto la demandada no celebró con la actora un contrato de transporte, sino que adquirió a través de ella, que actuó como comisionista y no como transportador, diversos pasajes aéreos y celebró contratos de transporte aéreo de pasajeros con distintas líneas aéreas. Por estas razones, la demandante carece de acción como transportista para demandar a “Greenpeace S.A.” En subsidio de las defensas anteriores, opone la excepción de pago de las obligaciones cobradas por la actora.

Respecto de la prescripción, el tribunal de primera instancia sostiene que a este respecto son aplicables una serie de normas que enuncia, ${ }^{11}$ y que no siendo esta acción de las que se refiere el Código Aeronáutico, resulta claramente aplicable la norma del artículo 822 del Código de Comercio, ${ }^{12}$ que establece un plazo de prescripción de cuatro años que no ha transcurrido a la fecha, por lo que procede rechazar esta excepción.

En cuanto al fondo, el juez estimó que de los antecedentes que obran en autos es posible concluir que la actora, en su carácter de empresa de transporte aéreo de carga y pasajeros, celebró diversos contratos de transporte aéreo con la demanda ${ }^{13}$, en virtud de los cuales la demandante se obligó y cumplió con su obligación de transportar o hacer transportar a ciertas personas vía aérea a diversos destinos. Ello fue cumplido por parte de la actora mediante la contratación de transporte con líneas aéreas a quienes hubo de pagar el valor de los pasajes correspondientes.

El tribunal desestimó la calidad de comisionista que le atribuye la demandada a la actora, toda vez que estimó que para que esto fuera efectivo se habría requerido de un

\footnotetext{
11 Código Aeronáutico, art. 166 y siguientes, Código de Comercio arts. 172, 219 y 220 y, supletoriamente, la Convención de Varsovia-La Haya, los tratados internacionales y el Código Civil, los usos y costumbres de la actividad aeronáutica y los principios generales de derecho.

12 "Las acciones que procedan de las obligaciones de que trata el presente Libro y que no tengan señalado un plazo especial de prescripción, durarán cuatro años."

${ }^{13}$ En calidad de cargador, según lo define el artículo 166, inciso $3^{\circ}$, es decir, "el que por cuenta propia o ajena encarga la conducción."
} 
contrato de comisión, cuya existencia y ejecución no fue acreditada. Por estas razones el tribunal rechaza esta defensa de la demandada. Rechazó asimismo la excepción de pago, por no haber sido demostrada por la demandada en el curso del juicio. Rechazó finalmente la excepción de prescripción y acogió la demanda. Conociendo del recurso de apelación, la Corte de Apelaciones de Santiago confirmó la sentencia de primera instancia.

La demandada recurrió de casación en el fondo, basado en el rechazo de la excepción de prescripción opuesta, fundando el error de derecho en la falta de aplicación del artículo 2.522 del Código Civil, que establece un plazo de prescripción de un año para la extinción de la acción interpuesta por el demandante. ${ }^{14}$ Señala que el Código Aeronáutico, que es el cuerpo legal que regula la materia de autos, no contiene una norma especial sobre prescripción de estos cobros, por lo que es menester recurrir una norma del mismo Código, la de su artículo $6^{\circ}$ que establece que "En lo no previsto en este código ni en los convenios o tratados internacionales aprobados por Chile, se aplicarán las normas de derecho común chileno, los usos y costumbres de la actividad aeronáutica y los principios generales de derecho." Así entiende el recurrente que las normas de derecho común aplicables en este caso corresponden al Código Civil y que son precisamente las que alegó con su excepción de prescripción. Considera que el artículo 822 del Código de Comercio regula la prescripción aplicable al contrato de transporte terrestres, pero no al aeronáutico.

Correspondió entonces a la Corte Suprema discernir si operaba la prescripción de corto tiempo del artículo 2.522 del Código Civil o la del artículo 822 del Código de Comercio. ${ }^{15}$ La Corte razona sobre el supuesto de que en este caso se trata de un contrato de transporte aéreo, regulado por el Código Aeronáutico. El artículo 126 de este código define este contrato como "aquel en virtud del cual una persona denominada transportador, se obliga por ciento precio, a conducir de un lugar a otro, por vía aérea, pasajeros o cosas ajenas y a entregar éstas a quienes vayan consignadas". Siendo así, y por aplicación del artículo $6^{\circ}$ del citado código, y en ausencia de otras normas sobre prescripción en dicho cuerpo legal, la Corte estima que "no hay demostración de normas válidas en lo que se refiere a los usos y costumbres y a los principios generales de derecho que basten para suplir la ausencia de norma especial." En consecuencia, solo cabe acudir al derecho común chileno que sea atingente a la solución del conflicto, que la Corte estima ser el capítulo V del libro II del Código de Comercio. Este capítulo, no obstante estar referido al transporte por tierra, ríos, lagos y canales navegables, es absolutamente similar al transporte aéreo en los demás requisitos o condiciones. Por ende, dada la naturaleza que la Corte atribuye al contrato de transporte aéreo, la legislación común aplicable sería precisamente el Código de Comercio, y en especial su artículo 822. Por estas consideraciones la Corte rechaza el recurso de casación en el fondo interpuesto por la demandada.

Este fallo se pronuncia con el voto en contra del ministro Sr. Juica, quien estuvo por acoger el recurso por cuanto, en su concepto, resulta evidente que cada tipo de contrato de transporte existe un grupo de normas diferentes que regulan de manera especial cada especie. Así, cada una de las regulaciones legales (el Código de Comercio

14 Prescribe en un año la acción de los mercaderes, proveedores y artesanos, por el precio de los artículos que despachan al menudeo. La de toda clase de personas por el precio de servicios que se prestan periódica o accidentalmente; como posaderos, acarreadores, mensajeros, barberos, etc. Código Civil, art. 2.522 .

15 Rol N¹876-2000, de 3 de Octubre de 2001. 
para el transporte terrestre, por ríos, lagos y canales navegables; el D.L. 2.222, Ley de Navegación, para el transporte marítimo y el Código Aeronáutico para el transporte aéreo) constituyen reglas especiales, por lo que ninguna reviste el carácter de común respecto de las otras, salvo en cuanto el legislador les dé tal carácter; y salvo remisiones expresas que el propio legislador ha efectuado en estas legislaciones especiales respecto de otras de igual naturaleza. ${ }^{16}$

Señala además que respecto de la prescripción de las acciones derivadas de los distintos tipos de transporte, también existen normas especiales, además de las normas de la legislación común contenidas en el Código Civil. Por ello, tratándose en el caso sub lite de un contrato de transporte aéreo, la legislación aplicable es la especial contenida en el Código Aeronáutico, que no contiene reglas de prescripción especiales para la acción de prescripción de cobro de pasajes. Dicho código contiene en su artículo $6^{\circ}$ una expresa remisión a las normas de derecho común chileno, las que en último término se encuentran contenidas en el Código Civil.

Así, la decisión de los jueces del fondo debió, en concepto del disidente, haber aplicado las reglas que para el arrendamiento de transporte contiene el Código Civil en sus artículos 2.013 y siguientes, en especial lo señalado en el artículo 2.021 del mismo Código, que señala que estas normas generales se observarán sin perjuicio de las especiales para los mismos objetos que se contienen en ordenanzas particulares relativas a cada especie de tráfico (Código Aeronáutico, Ley de Navegación) y en el Código de Comercio, el cual es aludido como norma especial. En conclusión, las normas del Código Civil relativas al arrendamiento de transporte son las normas de derecho común chileno que deben aplicarse a este caso.

Por ello, estimamos junto al ministro disidente que la norma de prescripción aplicable al caso que nos ocupa, es precisamente la del artículo 2.522 del Código Civil, que hace prescribir en una año la acción de los acarreadores por el precio de sus servicios.

En consecuencia, creemos que la excepción de prescripción recién referida debió haber sido acogida y, en consecuencia, debió haberse rechazado la demanda por este concepto.

\section{E. Declaración de quiebra por no pago de obligaciones que constan en cheques llamados “en garantía”}

Con fecha 3 de septiembre de 1999, fue declarada la quiebra de la Sociedad Maderas Nativas Limitada, en calidad de deudora comerciante del artículo 41 de la Ley de Quiebras. Dicha declaración fue solicitada por don Juan Urrutia Riesco y fundada en el no pago de dos cheques girados por la sociedad referida, cuyo valor alcanzaba en conjunto a los \$10.125.000. El solicitante señaló que notificada judicialmente de los protestos la sociedad deudora, no consignó fondos suficientes para cubrir el valor de los documentos citados y de las costas. Mediante la notificación judicial de los protestos de cheques, estos documentos adquirieron mérito ejecutivo.

\footnotetext{
16 Como en el caso del artículo 1.044 del Código de Comercio, que dispone que en los contratos de pasaje por vía marítima dentro de un mismo puerto, rada o bahía con fines recreativos o de turismo se regirá por las normas pertinentes del transporte terrestre del Título V del Libro II del Código de Comercio.
} 
El fallido recurrió de reposición en contra de dicha sentencia, basando su recurso en los siguiente fundamentos:

a) Que los cheques fundantes de la solicitud carecían de la calidad jurídica de tales, por haber sido girados con el objeto de garantizar el cumplimiento de la obligación de pagar el precio de una compraventa de bosque en pie y sin que este hecho importara novación. Agrega que la jurisprudencia es unánime en cuanto a que no revisten la calidad jurídica de cheques, los documentos girados como garantía de cumplimiento de obligaciones y no en pago de éstas.

b) Que los cheques fundantes de la declaración de quiebra fueron emitidos el 4 de diciembre de 1998, es decir, mucho más de un año antes de que fueran presentados a su cobro, razón por la cual dichos documentos se encontrarían caducados, de acuerdo con lo dispuesto en el artículo 23 de la Ley de Cuentas Corrientes Bancarias y Cheques.

El recurso de reposición es, en definitiva, rechazado, por cuanto se determinó que los cheques que motivaron la declaración de quiebra cumplen con los requisitos que el artículo 10 de la Ley de Cuentas Corrientes Bancarias y Cheques establece para que sean tales y además, que los cheques aparecen fechados el 20 de agosto y el 20 noviembre del año 1999, protestados en marzo de 1999 y dichos protestos notificados en abril del mismo año, razón por la cual no se encuentran caducados.

El tribunal sostiene finalmente que del análisis del contrato de compraventa de bosque en pie, no es posible concluir que dichos cheques hayan sido girados en garantía del pago de obligaciones.

El fallido recurrió de apelación en contra de la resolución recién aludida. Conociendo de este recurso, la Corte de Apelaciones de Concepción, utilizando un criterio en nuestro concepto errado, revocó la resolución recurrida, acogiendo el recurso especial de reposición interpuesto por la fallida en atención a que, a su juicio, si bien los cheques estaban fechados en agosto y noviembre de 1999, su fecha de entrega o 'giro real' correspondía a la fecha en que se suscribió el convenio modificatorio de la compraventa ya referida, que estipuló el pago de los valores mediante estos cheques que fueron 'postdatados,' hecho este último que confirma el nexo directo entre los cheques girados y el contrato suscrito entre las partes. Así las cosas, los documentos aludidos fueron cobrados y protestados más de tres meses después de la data de su 'giro real,' el 4 de diciembre de 1998, por lo que se encuentran caducados.

Además, la Corte agrega otro fundamento: los cheques no han sido jurídicamente protestados por cuanto los protestos tienen como fundamento una causal distinta de las que señala el artículo 22 de la Ley de Cuentas Corrientes Bancarias y Cheques, es decir, 'orden de no pago, incumplimiento comercial.' Debido a que el protesto se ha efectuado fuera de plazo de cobro del cheque y por causales que no contempla la ley, este sería improcedente, ya que el cheque ha dejado de ser jurídicamente tal.

La solicitante de la declaración de quiebra recurre de casación en el fondo en contra de la resolución de la Corte de Apelaciones de Concepción, señalando como errores de derecho de que adolece la misma, la infracción al artículo 10, que establece que el cheque es siempre pagadero a la vista y que cualquier mención contraria se tendrá por no escrita en relación con el artículo 23 de la Ley de Cuentas Corrientes Bancarias y Cheques. Explica que los cheques materia de autos no pudieron estimarse caducados por 
Sfeir - Jurisprudencia Corte Suprema 2001: Derecho Comercial

la Corte de Apelaciones, toda vez que ellos fueron presentados a su cobro (marzo de 1999) en una fecha anterior a la de su emisión (agosto y noviembre de 1999) y de acuerdo con el artículo 10 inciso $2^{\circ}$ de la ley del ramo, el cheque presentado a cobro antes del día indicado como fecha de emisión, es pagadero al día de la presentación. A mayor abundamiento el artículo 23, requiere que el cheque sea presentado a su cobro dentro de sesenta días contados desde la fecha su emisión, cuando el librado estuviere en la misma plaza y en noventa días cuando el librado estuviere en otra.

El recurrente de casación destacó además el hecho que el fallido no impugnara el crédito materia de la solicitud de quiebra dentro de los plazos legales existentes para ello. Por este motivo, el crédito se encuentra reconocido por el fallido y no puede ser objeto de reclamaciones posteriores (artículo 138 de la Ley de Quiebras), circunstancia suficiente para confirmar la sentencia que declaró la quiebra.

Finalmente, el recurrente señala que el fallido, una vez notificado de los protestos, no consignó fondos suficientes para su pago y el de las costas y tampoco tachó su firma puesta en los cheques, por lo que éstos adquirieron mérito ejecutivo. Lo anterior, hace que se cumplan todos los presupuestos necesarios para la confirmación de la sentencia declaratoria de la quiebra.

La Corte Suprema, restableciendo el recto criterio, acogió el recurso de casación en el fondo por estimar que los errores enunciados por la recurrente eran efectivos y que habían influido en lo dispositivo del fallo. ${ }^{17}$ En especial, la Corte estimó que no era procedente estimar que los cheques se encontraban caducados, toda vez que habían sido cobrados antes de la fecha en que estaban datados, debiendo el banco dar cumplimiento a la norma legal que establece que el cheque es pagadero a la vista. Además, tiene presente lo dispuesto en el artículo 22 de la ley del ramo que dispone que no servirá para eximirse de responsabilidad, la circunstancia de haberse girado el documento con una fecha posterior a su emisión. Con ello, la Corte entiende que dicha disposición acepta la posibilidad de que se giren cheques con fechas posteriores a su entrega, lo que no obsta al pago que el banco debe efectuar cuando estos documentos son presentados al cobro.

La doctrina está en armonía con esta posición. Al efecto se ha sostenido que:

el cheque no es un documento de valor indefinido en cuanto al tiempo, sino que tiene un plazo limitado para su presentación y cobro, caducando (plazo de caducidad y no de prescripción) una vez transcurrido el término fijado en la ley sin haberse presentado a cobro; el plazo comienza a contarse desde el día de la emisión del cheque (en realidad, desde el día indicado en el documento, que puede ser distinto al día en que realmente se emitio) y por lo mismo debe constar clara y determinadamente. ${ }^{18}$

Finalmente y respecto del segundo grupo de errores indicado en el recurso, la Corte concuerda con el recurrente señalando que la orden de no pago por incumplimiento de contrato no es una causal que permita revocar la orden de pago que representa el cheque, y que por ello, el protesto que aparece en los cheques de autos es eficaz para el ejercicio de las acciones que nacen de ellos. Así, demostrada su eficacia, los cheques cuyos protestos fueron notificados al fallido sin que éste depositara su valor ni tachara de falsa

\footnotetext{
${ }_{17}$ Rol N54-2001, de 20 de Noviembre de 2001.

${ }_{18}$ Guillermo Vásquez Méndez, Tratado sobre el Cheque, p. 105, Santiago: Ed. Jca. de Chile (2000) (el destacado es nuestro).
} 
REJ - Revista de Estudios de la Justicia - No 3 - Año 2003

su firma, constituyen títulos ejecutivos, de aquellos que permiten solicitar y obtener la quiebra de la empresa Sociedad Maderas Nativas Limitada.

Por todas estas razones, la Corte Suprema, acogió el recurso de casación referido, invalidando la sentencia de la Corte de Apelaciones de Concepción y dictando una sentencia de reemplazo que confirmó la declaración de quiebra de la empresa Sociedad Maderas Nativas Limitada. 